\title{
Accessible ring opening metathesis and atom transfer radical polymerization catalysts based on dimethyl sulfoxide ruthenium(II) complexes bearing $N$ - heterocyclic carbene ligands
}

\author{
André H.S. Idehara ${ }^{\mathrm{a}}$, Patrik D.S. Gois ${ }^{\mathrm{a}}$, Henrique Fernandez ${ }^{\mathrm{b}}$, Beatriz E. Goi ${ }^{\mathrm{a}}$, \\ Antonio E.H. Machado ${ }^{c}$, Benedito S. Lima-Neto ${ }^{\mathrm{b}}$, Valdemiro P. Carvalho Jr.,

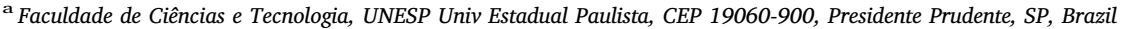 \\ ${ }^{\mathrm{b}}$ Instituto de Química de São Carlos, Universidade de São Paulo, CEP 13560-970, São Carlos, SP, Brazil \\ ${ }^{\mathrm{c}}$ Instituto de Química, UFU Universidade Federal de Uberlândia, CEP 38400-902, Uberlândia, MG, Brazil
}

\section{A R T I C L E I N F O}

\section{Keywords:}

Ruthenium complexes

ROMP

ATRP

Norbornene

Methyl methacrylate

\begin{abstract}
A B S T R A C T
Dimethyl sulfoxide ruthenium(II) complexes of $N$-heterocyclic carbenes derived from cycloalkylamines (cycloalkyl = cyclopentyl (1a), cyclohexyl (1b), cycloheptyl (1c), and cyclooctyl (1d)) were synthesized: $\left[\mathrm{RuCl}_{2}(\mathrm{~S}\right.$ dmso) $)_{2}$ (IPent)] (2a), $\left[\mathrm{RuCl}_{2}(\mathrm{~S}-\mathrm{dmso})_{2}(\mathrm{IHex})\right]$ (2b), $\left[\mathrm{RuCl}_{2}(\mathrm{~S}-\mathrm{dmso})_{2}(\mathrm{IHept})\right]$ (2c), and $\left[\mathrm{RuCl}_{2}(\mathrm{~S}-\mathrm{dmso})_{2}(\mathrm{IOct})\right]$ (2d). The imidazolium salts 1a-1d were characterized by FTIR, UV-vis, and ${ }^{1} \mathrm{H}$ and ${ }^{13} \mathrm{C}$ NMR spectroscopy, while their respective dimethyl sulfoxide ruthenium(II) complexes (2a-2d) were characterized by elemental analysis, FTIR, UV-vis, ${ }^{1} \mathrm{H}$ and ${ }^{13} \mathrm{C}$ NMR, and cyclic voltammetry. The complexes 2a-2d were evaluated as catalytic precursors for ROMP of norbornene (NBE) and for ATRP of methyl methacrylate (MMA). The polynorbornene (polyNBE) syntheses via ROMP using the complexes 2a-2d as pre-catalysts were evaluated under reaction conditions of $[\mathrm{EDA}] /[\mathrm{Ru}]=28(5 \mu \mathrm{L}),[\mathrm{NBE}] /[\mathrm{Ru}]=5000$ at $50^{\circ} \mathrm{C}$ as a function of time. The polymerization of MMA via ATRP was conducted using the complexes 2a-2d in the presence of ethyl 2-bromoisobutyrate (EBiB) as the initiator. All tests were using the molar ratio $[\mathrm{MMA}] /[\mathrm{EBiB}] /[\mathrm{Ru}]=1000 / 2 / 1$ and conducted at $85^{\circ} \mathrm{C}$. The linear correlation of $\ln \left([\mathrm{MMA}]_{0} /[\mathrm{MMA}]\right)$ and time clearly indicates that the concentration of radicals remains constant during the polymerization and that the ATRP of MMA mediated by $\mathbf{2 a - 2 d}$ proceeds in a controlled manner.
\end{abstract}

\section{Introduction}

Organometallic catalysts are designed and optimized to mediate a single reaction [1]. As the number of applications that require combinatorial synthetic protocols increases [2,3], it will become desirable for catalysts to mediate multiple, mechanistically distinct transformations directly or upon simple modification.

The preparation of new polymeric materials composed of segments that cannot be prepared by the same polymerization mechanism remains a challenge in synthetic polymer chemistry. Thus, many new strategies have emerged which are based on using substrates that are capable of initiating more than one type polymerization. While a few of these protocols permit the combination of all the desired monomers at the beginning of the polymerization, the majority require timed additions [4-9]. Furthermore, a number of organometallic complexes and co-catalysts must be included to control the polymerizations. Ultimately, it is desirable to develop new catalytic systems that have the ability to mediate several mechanistically different transformations, either directly or by simple modification; therefore requiring only the addition of desired monomers [10].

The ruthenium-based catalyst systems have been demonstrated to be effective for initiating the ring-opening metathesis polymerization (ROMP) of a variety of cyclic olefins and as mediators for atom-transfer radical polymerization (ATRP) of vinyl monomers [11-16]. The Grubbs' ruthenium benzylidene, $\mathrm{Cl}_{2}\left(\mathrm{PCy}_{3}\right)_{2} \mathrm{Ru}=\mathrm{CHPh}$, known as a very active olefin metathesis catalyst, showed to be also capable of performing ATRP of styrene and methyl methacrylates [17].

In light of these observations, we became interested in the development of Ru catalysts that can do both ROMP and ATRP reactions. During the past 15 years, easy and efficient synthesis of rutheniumbased ROMP catalysts has been developed by our group [18-24]. Recently, some of the complexes have been successfully applied to controlled/living radical polymerizations of vinyl monomers [25-27].

Herein, for the first time, we report the facile preparation and

\footnotetext{
* Corresponding author.

E-mail address: valdemiro@fct.unesp.br (V.P. Carvalho).
} 


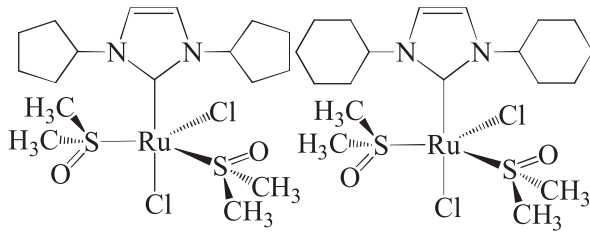

$2 \mathbf{a}$

$\mathbf{2 b}$

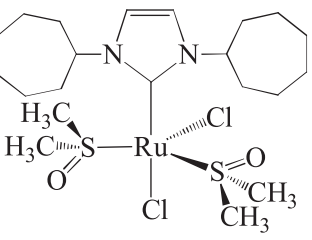

2c

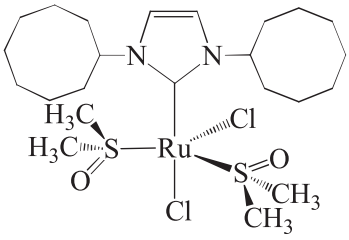

2d

Fig. 1. Illustration of the NHC ruthenium(II) complexes 2a-2d.

evaluation of dimethyl sulfoxide-ruthenium(II) complexes bearing NHC ligands substituted with cycloalkyl groups: cyclopentyl (2a), cyclohexyl (2b), cycloheptyl (2c), and cyclooctyl (2d) (Fig. 1), as catalyst precursors for ROMP of norbornene (NBE) and ATRP of methyl methacrylate (MMA). Ethyl diazoacetate (EDA) was used as carbene source for ROMP and ethyl 2-bromoisobutyrate (EBiB) was used as initiator for ATRP. The goal was to observe the influence of cycloalkyl groups and its effects on catalytic activity of the studies complexes, discussing the $\sigma$-donor ability and steric hindrance, obtaining resources to understand the factors that influence the efficiency of both reactions.

\section{Experimental}

\subsection{General remarks}

Unless otherwise stated, all syntheses and manipulations were performed under nitrogen atmosphere following standard Schlenk techniques. Solvents were distilled from appropriate drying agents and deoxygenated prior to use. Methyl methacrylate (MMA) was washed with $5 \% \mathrm{NaOH}$ solution, dried over anhydrous $\mathrm{MgSO}_{4}$, vacuum distilled from $\mathrm{CaH}_{2}$ and stored under nitrogen at $-18^{\circ} \mathrm{C}$ before use. Glyoxal ( $40 \%$ aqueous solution) was stored in a cold room at $+4^{\circ} \mathrm{C}$. $\mathrm{RuCl}_{3} \cdot \mathrm{xH}_{2} \mathrm{O}, \quad 2,2,6,6$-tetramethyl-1-piperidinoxyl (TEMPO), tetrabutylammonium hexafluorophosphate $\left(n-\mathrm{Bu}_{4} \mathrm{NPF}_{6}\right)$, ferrocene $(\mathrm{Fc})$, norbornene (NBE), ethyl diazoacetate (EDA), cyclopentylamine, cyclohexylamine, cycloheptylamine, cyclooctylamine, paraformaldehyde, tetrafluoroboric acid, dimethylsulfoxide, and ethyl 2-bromoisobutyrate (EBiB) were obtained from Aldrich and used as acquired. The $\left[\mathrm{RuCl}_{2}(\mathrm{~S}-\right.$ $\left.\mathrm{dmso})_{3}(\mathrm{O}-\mathrm{dmso})\right]$ complex was prepared following the literature and its purity was checked by satisfactory elemental analysis and spectroscopic examination (NMR, FTIR, and EPR) [28].

\subsection{Analyses}

Elemental analyses were performed with a Perkin-Elmer CHN 2400 at the Elemental Analysis Laboratory of Institute of Chemistry - USP. ESR measurements from solid sample were conducted at $77 \mathrm{~K}$ using a Bruker ESR 300C apparatus (X-band) equipped with a TE102 cavity and an HP 52152A frequency counter. The FTIR spectra were obtained on a Bomem FTIR MB 102. Electronic spectra were recorded on a Shimadzu (model UV-1800) spectrophotometer, using $1 \mathrm{~cm}$ path length quartz cells. The ${ }^{1} \mathrm{H}$ and ${ }^{13} \mathrm{C}$ NMR spectra were obtained in $\mathrm{CDCl}_{3}$ at $298 \mathrm{~K}$ on a Bruker DRX-400 spectrometer operating at 400.13 and $100.62 \mathrm{MHz}$, respectively. Chemical shifts are listed in parts per million downfield from TMS and are referenced from the solvent peaks or TMS. Conversion was determined from the concentration of residual monomer measured by gas chromatography (GC) using a Shimadzu GC2010 gas chromatograph equipped with a flame ionization detector and a $30 \mathrm{~m}(0.53 \mathrm{~mm}$ I.D., $0.5 \mu \mathrm{m}$ film thickness $)$ SPB-1 Supelco fused silica capillary column. Anisole was added to polymerization and used as an internal standard. Analysis conditions: injector and detector temperature, $250{ }^{\circ} \mathrm{C}$; temperature program, $40^{\circ} \mathrm{C}(4 \mathrm{~min}), 20^{\circ} \mathrm{C} \mathrm{min}{ }^{-1}$ until $200^{\circ} \mathrm{C}, 200^{\circ} \mathrm{C}(2 \mathrm{~min})$. The molecular weights and the molecular weight distribution of the polymers were determined by gel permeation chromatography using a Shimadzu Prominence LC system equipped with a LC-20AD pump, a DGU-20A5 degasser, a CBM-20A communication module, a CTO-20A oven at $40{ }^{\circ} \mathrm{C}$ and a RID-10A detector equipped with two Shimadzu column (GPC-805: $30 \mathrm{~cm}$, $\emptyset=8.0 \mathrm{~mm}$ ). The retention time was calibrated with standard monodispersed polystyrene using HPLC-grade THF as an eluent at $40{ }^{\circ} \mathrm{C}$ with a flow rate of $1.0 \mathrm{~mL} \mathrm{~min}^{-1}$. Electrochemical measurements were performed using an Autolab PGSTAT204 potentiostat with a stationary platinum disk and a wire as working and auxiliary electrodes, respectively. The reference electrode was $\mathrm{Ag} / \mathrm{AgCl}$. The measurements were performed at $25^{\circ} \mathrm{C} \pm 0.1$ in $\mathrm{CH}_{2} \mathrm{Cl}_{2}$ with $0.1 \mathrm{~mol} \mathrm{~L}^{-1}$ of $n-\mathrm{Bu}_{4} \mathrm{NPF}_{6}$.

\subsection{General procedure for the preparation of $N$-heterocyclic ligands}

To prepare the $N$-heterocyclic carbenes (NHC) ligands 1a-1d, A $50 \mathrm{~mL}$ round-bottom flask equipped with a magnetic stirring bar and a stopper was charged with cycloalkylamine $(10 \mathrm{mmol})$, toluene $(10 \mathrm{~mL})$, and paraformaldehyde $(10 \mathrm{mmol})$. The resulting milky suspension was stirred for $30 \mathrm{~min}$ at room temperature until the solid was almost completely dissolved. The mixture was cooled to $0{ }^{\circ} \mathrm{C}$ in an ice/water bath and a second equivalent of cycloalkylamine $(10 \mathrm{mmol})$ was added. The resulting yellow solution was stirred for $10 \mathrm{~min}$ at $0{ }^{\circ} \mathrm{C}$ before tetrafluoroboric acid ( $48 \%$ aqueous solution, $12.5 \mathrm{mmol}$ ) was added portionwise in $15 \mathrm{~min}$. The cooling bath was removed and glyoxal (40\% aqueous solution, $10 \mathrm{mmol}$ ) was added. The resulting cloudy mixture was stirred overnight (ca. $12 \mathrm{~h}$ ) in an oil bath at $50^{\circ} \mathrm{C}$. After cooling to room temperature, dichloromethane $(10 \mathrm{~mL})$ and water $(20 \mathrm{~mL})$ were added and the layers were separated. The aqueous phase was extracted with 3 portions of dichloromethane $(10 \mathrm{~mL}$ each). The organic layers were combined and dried over $\mathrm{MgSO}_{4}$. After evaporation of the solvent, the beige residue was recrystallized from isopropanol to afford pure 1,3-dicycloalkylimidazolium tetrafluoroborate.

\subsubsection{1,3-dicyclopentylimidazolium tetrafluoroborate 1 a}

Paraformaldehyde $(0.4 \mathrm{~g}, 10.0 \mathrm{mmol})$, cyclopentylamine $(2.0 \mathrm{~mL}$, $20.0 \mathrm{mmol})$, glyoxal $(1.1 \mathrm{~mL}, 10 \mathrm{mmol})$, and tetrafluoroboric acid $(1.1 \mathrm{~g}, 12.5 \mathrm{mmol})$ afforded $1.27 \mathrm{~g}(67 \%)$ of the title compound as white needles (a) UV-vis: $\lambda_{\max (\mathrm{n})}(\mathrm{nm}), \varepsilon_{\max (\mathrm{n})}\left[\mathrm{M}^{-1} \mathrm{~cm}^{-1}\right]: \lambda_{\max (1)}(241 \mathrm{~nm})$, $\varepsilon_{\max (1)}$ [3200]; $\lambda_{\max (2)}$ (324), $\varepsilon_{\max (2)}$ [1200]; $\lambda_{\max (3)}$ (374), $\varepsilon_{\max (3)}$ [670]; (b) FTIR (KBr): $\nu_{\mathrm{x}}\left(\mathrm{cm}^{-1}\right): \nu \mathrm{C}=\mathrm{C}(1562), \nu \mathrm{C}=\mathrm{N}(1634), \nu \mathrm{C}-\mathrm{H}$ (2934); (c). ${ }^{1} \mathrm{H}$ NMR (400 MHz, $\mathrm{CDCl}_{3}$ ): $\delta=8.93$ (s, $\left.1 \mathrm{H}, \mathrm{CH} \mathrm{Im}\right), 7.40$ (s, $\left.2 \mathrm{H}, \mathrm{CH}_{4,5} \mathrm{Im}\right), 4.79(\mathrm{~m}, 2 \mathrm{H}, \mathrm{NCH}), 2.34\left(\mathrm{~m}, 4 \mathrm{H}, \mathrm{CH}_{2}{ }^{\text {Pentyl }}\right), 1.89$ (m, $\left.8 \mathrm{H}, \mathrm{CH}_{2}{ }^{\text {Pentyl }}\right), 1.76$ (m, $\left.4 \mathrm{H}, \mathrm{CH}_{2}{ }^{\text {Pentyl }}\right) .{ }^{13} \mathrm{C}$ NMR $\left(100 \mathrm{MHz}, \mathrm{CDCl}_{3}\right)$ : $\delta=134.3\left(\mathrm{CH}^{2} \mathrm{Im}\right), 120.8\left(\mathrm{CH}^{4,5} \mathrm{Im}\right), 61.5\left(\mathrm{CH}^{\text {Pentyl }}\right), 33.2\left(\mathrm{CH}_{2}{ }^{\text {Pentyl }}\right)$, $23.7\left(\mathrm{CH}_{2}{ }^{\text {Pentyl }}\right) \mathrm{ppm}$.

\subsubsection{1,3-dicyclohexylimidazolium tetrafluoroborate $\mathbf{1 b}$}

Paraformaldehyde $(0.4 \mathrm{~g}, 10.0 \mathrm{mmol})$, cyclohexylamine $(2.3 \mathrm{~mL}$, $20.0 \mathrm{mmol})$, glyoxal $(1.1 \mathrm{~mL}, 10 \mathrm{mmol})$, and tetrafluoroboric acid $(1.1 \mathrm{~g}, 12.5 \mathrm{mmol})$ afforded $1.5 \mathrm{~g}(64 \%)$ of the title compound as white needles. (a) UV-vis: $\lambda_{\max (\mathrm{n})}(\mathrm{nm}), \varepsilon_{\max (\mathrm{n})}\left[\mathrm{M}^{-1} \mathrm{~cm}^{-1}\right]: \lambda_{\max (1)}(241)$, $\varepsilon_{\max (1)}$ [3180]; $\lambda_{\max (2)}$ (282), $\varepsilon_{\max (2)}$ [1780]; $\lambda_{\max (3)}$ (325), $\varepsilon_{\max (3)}$ [1650]; (b) FTIR (KBr): $\nu_{\mathrm{x}}\left(\mathrm{cm}^{-1}\right): \nu \mathrm{C}=\mathrm{C}$ (1559), $\nu \mathrm{C}=\mathrm{N}(1635), \nu \mathrm{C}-\mathrm{H}$ (2928); (c). ${ }^{1} \mathrm{H}$ NMR (400 MHz, $\mathrm{CDCl}_{3}$ ): $\delta=8.92$ (s, $1 \mathrm{H}, \mathrm{CH}^{2} \mathrm{Im}$ ), 7.47 (s, 2H, CH $\left.{ }^{4,5} \mathrm{Im}\right), 4.35-4.29(\mathrm{~m}, 2 \mathrm{H}, \mathrm{NCH}), 2.19-2.16(\mathrm{~m}, 4 \mathrm{H}$, $\left.\mathrm{CH}_{2}{ }^{\mathrm{Hexyl}}\right), 1.92-1.89\left(\mathrm{~m}, 4 \mathrm{H}, \mathrm{CH}_{2}{ }^{\mathrm{Hexyl}}\right), 1.74-1.67\left(\mathrm{~m}, 6 \mathrm{H}, \mathrm{CH}_{2}{ }^{\mathrm{Hexyl}}\right)$, 1.52-1.42 (m, 4H, $\mathrm{CH}_{2}{ }^{\text {Hexyl }}$ ), $1.33-1.25\left(\mathrm{~m}, 2 \mathrm{H}, \mathrm{CH}_{2}{ }^{\text {Hexyl }}\right) \mathrm{ppm} .{ }^{13} \mathrm{C}$ NMR $\left(100 \mathrm{MHz}, \mathrm{CDCl}_{3}\right): \delta=133.0\left(\mathrm{CH}_{2} \mathrm{Im}\right), 120.5\left(\mathrm{CH}_{4,5} \mathrm{Im}\right), 60.1$ 
$\left(\mathrm{CH}^{\text {Hexyl }}\right), 33.3\left(\mathrm{CH}_{2}{ }^{\mathrm{Hexyl}}\right), 25.0\left(\mathrm{CH}_{2}{ }^{\mathrm{Hexyl}}\right), 24.6\left(\mathrm{CH}_{2}{ }^{\mathrm{Hexyl}}\right) \mathrm{ppm}$. These NMR data matched those reported in the literature.[29,30]

\subsubsection{1,3-dicycloheptylimidazolium tetrafluoroborate 1c}

Paraformaldehyde $(0.4 \mathrm{~g}, 10.0 \mathrm{mmol})$, cycloheptylamine $(2.6 \mathrm{~mL}$, $20.0 \mathrm{mmol})$, glyoxal $(1.1 \mathrm{~mL}, 10 \mathrm{mmol})$, and tetrafluoroboric acid $(1.1 \mathrm{~g}, 12.5 \mathrm{mmol})$ afforded $0.91 \mathrm{~g}(72 \%)$ of the title compound as white needles. (a) UV-vis: $\lambda_{\max (\mathrm{n})}(\mathrm{nm}), \varepsilon_{\max (\mathrm{n})}\left[\mathrm{M}^{-1} \mathrm{~cm}^{-1}\right]: \lambda_{\max (1)}(241 \mathrm{~nm})$, $\varepsilon_{\max (1)}$ [3195]; $\lambda_{\max (2)}$ (325), $\varepsilon_{\max (2)}$ [720]; $\lambda_{\max (3)}$ (364), $\varepsilon_{\max (3)}$ [581]; (b) FTIR (KBr): $\nu_{\mathrm{x}}\left(\mathrm{cm}^{-1}\right): \nu \mathrm{C}=\mathrm{C}(1552), \nu \mathrm{C}=\mathrm{N}$ (1630), $\nu \mathrm{C}-\mathrm{H}$ (2921); (c) ${ }^{1} \mathrm{H}$ NMR (400 MHz, $\mathrm{CDCl}_{3}$ ): $\delta=8.95$ (s, $1 \mathrm{H}, \mathrm{CH} \mathrm{Im}$ ), 7.38 (s, $2 \mathrm{H}$, $\mathrm{CH}_{4,5} \mathrm{Im}$ ), 4.47 (m, 2H, NCH), 2.14 (m, 4H, $\mathrm{CH}_{2}{ }^{\mathrm{Heptyl}}$ ), 1.92 (m, 4H, $\left.\mathrm{CH}_{2}{ }^{\mathrm{Heptyl}}\right), 1.78\left(\mathrm{~m}, 5 \mathrm{H}, \mathrm{CH}_{2}{ }^{\text {Heptyl }}\right), 1.62\left(\mathrm{~m}, 12 \mathrm{H}, \mathrm{CH}_{2}{ }^{\text {Heptyl }}\right.$ ) ppm. ${ }^{13} \mathrm{C}$ NMR $\left(100 \mathrm{MHz}, \mathrm{CDCl}_{3}\right): \delta=133.2\left(\mathrm{CH}^{2} \mathrm{Im}\right), 120.3\left(\mathrm{CH}^{4,5} \mathrm{Im}\right), 62.5$ $\left(\mathrm{CH}^{\mathrm{Heptyl}}\right), 35.7\left(\mathrm{CH}_{2}{ }^{\mathrm{Heptyl}}\right), 27.0\left(\mathrm{CH}_{2}{ }^{\mathrm{Heptyl}}\right), 24.0\left(\mathrm{CH}_{2}{ }^{\mathrm{Heptyl}}\right) \mathrm{ppm}$.

\subsubsection{1,3-dicyclooctylimidazolium tetrafluoroborate 1d}

Paraformaldehyde $(0.4 \mathrm{~g}, 10.0 \mathrm{mmol})$, cyclooctylamine $(2.8 \mathrm{~mL}$, $20.0 \mathrm{mmol})$, glyoxal $(1.1 \mathrm{~mL}, 10 \mathrm{mmol})$, and tetrafluoroboric acid $(1.1 \mathrm{~g}, 12.5 \mathrm{mmol})$ afforded $0.88 \mathrm{~g}(74 \%)$ of the title compound as white needles. (a) UV-vis: $\lambda_{\max (\mathrm{n})}(\mathrm{nm}), \varepsilon_{\max (\mathrm{n})}\left[\mathrm{M}^{-1} \mathrm{~cm}^{-1}\right]: \lambda_{\max (1)}(244 \mathrm{~nm})$, $\varepsilon_{\max (1)}$ [3860]; $\lambda_{\max (2)}$ (316), $\varepsilon_{\max (2)}$ [2810]; $\lambda_{\max (3)}$ (380), $\varepsilon_{\max (3)}$ [1890]; (b) FTIR (KBr): $\nu_{\mathrm{x}}\left(\mathrm{cm}^{-1}\right): \nu \mathrm{C}=\mathrm{C}$ (1558), $\nu \mathrm{C}=\mathrm{N}(1644), \nu \mathrm{C}-\mathrm{H}$ (2923); (c) ${ }^{1} \mathrm{H}$ NMR (400 MHz, $\mathrm{CDCl}_{3}$ ): $\delta=8.94$ (s, $1 \mathrm{H}, \mathrm{CH} \mathrm{Im}$ ), 7.29 (s, $\left.2 \mathrm{H}, \mathrm{CH}_{4,5} \mathrm{Im}\right), 4.54(\mathrm{~m}, 2 \mathrm{H}, \mathrm{NCH}), 1.98\left(\mathrm{~m}, 8 \mathrm{H}, \mathrm{CH}_{2}{ }^{\text {Octyl }}\right), 1.72(\mathrm{~m}, 5 \mathrm{H}$, $\left.\mathrm{CH}_{2}{ }^{\mathrm{Octyl}}\right), 1.57\left(\mathrm{~m}, 15 \mathrm{H}, \mathrm{CH}_{2}{ }^{\mathrm{Octyl}}\right)$ ppm. $\left.{ }^{13} \mathrm{C} \mathrm{NMR} \mathrm{(100} \mathrm{MHz,} \mathrm{CDCl}_{3}\right)$ : $\delta=133.7\left(\mathrm{CH}_{2} \mathrm{Im}\right), 120.3\left(\mathrm{CH}_{4,5} \mathrm{Im}\right), 61.7\left(\mathrm{CH}^{\text {Octyl }}\right), 33.5\left(\mathrm{CH}_{2}{ }^{\mathrm{Octyl}}\right)$, $26.3\left(\mathrm{CH}_{2}{ }^{\mathrm{Octyl}}\right), 25.4\left(\mathrm{CH}_{2}{ }^{\mathrm{Octyl}}\right), 23.8\left(\mathrm{CH}_{2}{ }^{\mathrm{Octyl}}\right) \mathrm{ppm}$.

\subsection{General procedure for the preparation of NHC-Ru complexes}

An oven-dried $100 \mathrm{~mL}$ round-bottom flask equipped with a magnetic stirring bar and capped with a three-way stopcock was charged with an 1,3-dicycloalkylimidazolium tetrafluoroborate (1a-1d) (1 equiv), 95\% sodium hydride (1.2 equiv) and a catalytic amount of potassium tert-butoxide. The reactor was purged of air by applying three vacuum/argon cycles before dry THF was added. The resulting suspension was stirred $2 \mathrm{~h}$ at room temperature, it was then allowed to settle for $1 \mathrm{~h}$. The supernatant solution was filtered through Celite and transferred with a cannula under inert atmosphere into a two neck $100 \mathrm{~mL}$ round-bottom flask equipped with a magnetic stirring bar and capped with a three-way stopcock containing a solution of $\left[\mathrm{RuCl}_{2}(\mathrm{~S}\right.$ dmso) $\left.{ }_{3}(\mathrm{O}-\mathrm{dmso})\right]$ (1 equiv) in dichloromethane $(10 \mathrm{~mL})$. After $4 \mathrm{~h}$ of stirring at room temperature, the solvent was evaporated under vacuum. The residue was washed with $n$-pentane $(20 \mathrm{~mL})$. It was dried under high vacuum and recrystallized by slow diffusion of pentane into concentrated dichloromethane solution of the complex.

\subsubsection{Complex $2 a$}

$\left[\mathrm{RuCl}_{2}(\mathrm{~S}-\mathrm{dmso})_{3}(\mathrm{O}-\mathrm{dmso})\right]$ complex (350 mg, $\left.0.72 \mathrm{mmol}\right), \mathrm{NHC} 1 \mathrm{a}$ (205 mg, $1 \mathrm{mmol}$ ), and THF (50 mL) afforded $368 \mathrm{mg}(84 \%)$ of the title complex as a yellow solid: anal. calculated for $\mathrm{C}_{17} \mathrm{H}_{32} \mathrm{Cl}_{2} \mathrm{~N}_{2} \mathrm{O}_{2} \mathrm{RuS}_{2}$ was $38.34 \mathrm{C}, 6.07 \mathrm{H}$ and $5.26 \% \mathrm{~N}$; found: $38.45 \mathrm{C}, 6.23 \mathrm{H}$ and $5.12 \% \mathrm{~N}$. (a) UV-vis: $\lambda_{\max (\mathrm{n})}(\mathrm{nm}), \varepsilon_{\max (\mathrm{n})}\left[\mathrm{M}^{-1} \mathrm{~cm}^{-1}\right]: \lambda_{\max (1)}(243), \varepsilon_{\max (1)}$ [4837]; $\lambda_{\max (2)}$ (330), $\varepsilon_{\max (2)}$ [389]; (b) FTIR (CsI): $\nu_{\mathrm{x}}\left(\mathrm{cm}^{-1}\right): \nu \mathrm{C}=\mathrm{C}$ (1552), $\nu \mathrm{C}=\mathrm{N}$ (1649), $\nu \mathrm{S}=\mathrm{O}$ (1102, 1022), $\nu \mathrm{Ru}-\mathrm{S}$ (428); (c). ${ }^{1} \mathrm{H}$ NMR $\left(400 \mathrm{MHz}, \mathrm{CDCl}_{3}\right): \delta=7.20$ (s, $\left.1 \mathrm{H}, \mathrm{CH}_{4,5} \mathrm{Im}\right), 5.36(\mathrm{~m}, 2 \mathrm{H}, \mathrm{NCH}), 3.48$ (s, $12 \mathrm{H}, \mathrm{CH}_{3} \mathrm{~S}$-DMSO), 2.31 (m, $2 \mathrm{H}, \mathrm{CH}_{2}{ }^{\text {Pentyl }}$ ), 1.81 (m, $2 \mathrm{H}, \mathrm{CH}_{2}{ }^{\text {Pentyl }}$ ), 1.74 (m, 4H, $\mathrm{CH}_{2}{ }^{\text {Pentyl }}$ ), 1.69 (m, $2 \mathrm{H}, \mathrm{CH}_{2}{ }^{\text {Pentyl }}$ ), 1.64 (s, 6H, $\mathrm{CH}_{2}{ }^{\text {Pentyl }}$ ) ppm. $\left.{ }^{13} \mathrm{C} \mathrm{NMR} \mathrm{(100} \mathrm{MHz,} \mathrm{CDCl}_{3}\right): \delta=138.3\left(\mathrm{Im}-\mathrm{C}_{2}\right), 118.5\left(\mathrm{Im}^{-\mathrm{C}_{4,5}}\right)$, 60.8 (CHN), $46.1\left(\mathrm{CH}_{3}\right.$-S-dmso), $33.5\left(\mathrm{CH}_{2}{ }^{\text {Pentyl }}\right), 24.0\left(\mathrm{CH}_{2}{ }^{\text {Pentyl }}\right) \mathrm{ppm}$. EPR: no signal was observed.

\subsubsection{Complex $2 b$}

$\left[\mathrm{RuCl}_{2}(\mathrm{~S}-\mathrm{dmso})_{3}(\mathrm{O}-\mathrm{dmso})\right]$ complex (350 mg, $\left.0.72 \mathrm{mmol}\right), \mathrm{NHC} \mathbf{1 b}$ (233 $\mathrm{mg}, 1 \mathrm{mmol})$, and THF (50 mL) afforded $374 \mathrm{mg}(81 \%)$ of the title complex as a yellow solid: anal. calculated for $\mathrm{C}_{19} \mathrm{H}_{36} \mathrm{Cl}_{2} \mathrm{~N}_{2} \mathrm{O}_{2} \mathrm{RuS}_{2}$ was 40.71C, $6.47 \mathrm{H}$ and $5.00 \% \mathrm{~N}$; found: $40.92 \mathrm{C}, 6.54 \mathrm{H}$ and $4.88 \% \mathrm{~N}$. (a) UV-vis: $\lambda_{\max (\mathrm{n})}(\mathrm{nm}), \varepsilon_{\max (\mathrm{n})}\left[\mathrm{M}^{-1} \mathrm{~cm}^{-1}\right]: \lambda_{\max (1)}$ (245), $\varepsilon_{\max (1)}$ [8437]; $\lambda_{\max (2)}$ (355), $\varepsilon_{\max (2)}$ [651]; (b) FTIR (CsI): $\nu_{\mathrm{x}}\left(\mathrm{cm}^{-1}\right): \nu \mathrm{C}=\mathrm{C}$ (1552), $\nu \mathrm{C}=\mathrm{N}(1644), \nu \mathrm{S}=\mathrm{O}(1102,1018), \nu \mathrm{Ru}-\mathrm{S}$ (428); (c). ${ }^{1} \mathrm{H} \mathrm{NMR}$ (400 MHz, $\mathrm{CDCl}_{3}$ ): $\delta=7.17$ (s, 2H, $\mathrm{CH}_{4,5} \mathrm{Im}$ ), 5.02 (m, 2H, NCH), 3.53 (s, 12H, $\mathrm{CH}_{3} \mathrm{~S}$-DMSO), $2.21\left(\mathrm{~m}, 2 \mathrm{H}, \mathrm{CH}_{2}{ }^{\mathrm{Hexyl}}\right.$ ), $1.86\left(\mathrm{~m}, 4 \mathrm{H}, \mathrm{CH}_{2}{ }^{\mathrm{Hexyl}}\right.$ ), $1.76\left(\mathrm{~s}, 6 \mathrm{H}, \mathrm{CH}_{2}{ }^{\mathrm{Hexyl}}\right), 1.56\left(\mathrm{~m}, 10 \mathrm{H}, \mathrm{CH}_{2}{ }^{\mathrm{Hexyl}}\right) \mathrm{ppm} .{ }^{13} \mathrm{C} \mathrm{NMR}$ $\left(100 \mathrm{MHz}, \mathrm{CDCl}_{3}\right): \delta=137.5\left(\mathrm{Im}-\mathrm{C}_{2}\right), 117.9\left(\mathrm{Im}-\mathrm{C}_{4,5}\right), 58.7(\mathrm{CHN})$, $46.1\left(\mathrm{CH}_{3}\right.$-S-dmso), $33.4\left(\mathrm{CH}_{2}{ }^{\text {hexyl }}\right), 24.9\left(\mathrm{CH}_{2}{ }^{\text {hexyl }}\right)$ ppm. EPR: no signal was observed.

\subsubsection{Complex $2 c$}

$\left[\mathrm{RuCl}_{2}(\mathrm{~S}-\mathrm{dmso})_{3}(\mathrm{O}-\mathrm{dmso})\right]$ complex (350 mg, $\left.0.72 \mathrm{mmol}\right), \mathrm{NHC} 1 \mathrm{c}$ (261 mg, $1 \mathrm{mmol}$ ), and THF (50 mL) afforded $375 \mathrm{mg}(78 \%)$ of the title complex as a yellow solid: anal. calculated for $\mathrm{C}_{21} \mathrm{H}_{40} \mathrm{Cl}_{2} \mathrm{~N}_{2} \mathrm{O}_{2} \mathrm{RuS}_{2}$ was 41.85C, $6.85 \mathrm{H}$ and $4.76 \% \mathrm{~N}$; found: $42.02 \mathrm{C}, 6.98 \mathrm{H}$ and $4.63 \% \mathrm{~N}$ (a) UV-vis: $\lambda_{\max (\mathrm{n})}(\mathrm{nm}), \varepsilon_{\max (\mathrm{n})}\left[\mathrm{M}^{-1} \mathrm{~cm}^{-1}\right]: \lambda_{\max (1)}$ (244), $\varepsilon_{\max (1)}$ [4239]; $\lambda_{\max (2)}$ (360), $\varepsilon_{\max (2)}$ [291]; (b) FTIR (CsI): $\nu_{\mathrm{x}}\left(\mathrm{cm}^{-1}\right): \nu \mathrm{C}=\mathrm{C}(1549)$, $\nu \mathrm{C}=\mathrm{N}$ (1651), $\nu \mathrm{S}=\mathrm{O}(1102,1017), \nu \mathrm{Ru}-\mathrm{S}$ (428); (c). ${ }^{1} \mathrm{H}$ NMR (400 MHz, $\mathrm{CDCl}_{3}$ ): $\delta=7.16$ (s, $2 \mathrm{H}, \mathrm{CH}_{4,5} \mathrm{Im}$ ), 5.00 (m, $2 \mathrm{H}, \mathrm{NCH}$ ), 3.56 (s, 12H, $\mathrm{CH}_{3}$ S-DMSO), 1.92-1.82 (m, 4H, $\left.\mathrm{CH}_{2}{ }^{\mathrm{Heptyl}}\right), 1.83-1.75(\mathrm{~m}, 6 \mathrm{H}$, $\left.\mathrm{CH}_{2}{ }^{\mathrm{Heptyl}}\right), 1.74-1.70\left(\mathrm{~m}, 6 \mathrm{H}, \mathrm{CH}_{2}{ }^{\mathrm{Heptyl}}\right), 1.66-1.57$ (m, 8H, $\mathrm{CH}_{2}{ }^{\mathrm{Heptyl}}$ ) ppm. ${ }^{13} \mathrm{C}$ NMR $\left(100 \mathrm{MHz}, \mathrm{CDCl}_{3}\right):{ }^{13} \mathrm{C} \mathrm{NMR}\left(100 \mathrm{MHz}, \mathrm{CDCl}_{3}\right)$ : $\delta=136.9\left(\mathrm{Im}-\mathrm{C}_{2}\right), 118.3\left(\mathrm{Im}-\mathrm{C}_{4,5}\right), 61.5(\mathrm{CHN}), 46.1\left(\mathrm{CH}_{3}\right.$-S-dmso), $35.8\left(\mathrm{CH}_{2}{ }^{\text {heptyl }}\right), 27.2\left(\mathrm{CH}_{2}{ }^{\text {heptyl }}\right), 24.0\left(\mathrm{CH}_{2}{ }^{\text {heptyl }}\right)$ ppm. EPR: no signal was observed.

\subsubsection{Complex $2 d$}

$\left[\mathrm{RuCl}_{2}(\mathrm{~S}-\mathrm{dmso})_{3}\right.$ (O-dmso)] complex (350 mg, $\left.0.72 \mathrm{mmol}\right), \mathrm{NHC} \mathbf{1 d}$ (289 $\mathrm{mg}, 1 \mathrm{mmol})$, and THF $(50 \mathrm{~mL})$ afforded $352 \mathrm{mg}(70 \%)$ of the title complex as a yellow solid: anal. calculated for $\mathrm{C}_{23} \mathrm{H}_{44} \mathrm{Cl}_{2} \mathrm{~N}_{2} \mathrm{O}_{2} \mathrm{RuS}_{2}$ was 44.79C, $7.19 \mathrm{H}$ and $4.54 \% \mathrm{~N}$; found: $45.02 \mathrm{C}, 7.31 \mathrm{H}$ and $4.44 \% \mathrm{~N}$. (a) UV-vis: $\lambda_{\max (\mathrm{n})}(\mathrm{nm}), \varepsilon_{\max (\mathrm{n})}\left[\mathrm{M}^{-1} \mathrm{~cm}^{-1}\right]: \lambda_{\max (1)}(244), \varepsilon_{\max (1)}$ [7100]; $\lambda_{\max (2)}$ (336), $\varepsilon_{\max (2)}$ [1013]; (b) FTIR (CsI): $\nu_{\mathrm{x}}\left(\mathrm{cm}^{-1}\right): \nu \mathrm{C}=\mathrm{C}(1548)$, $\nu \mathrm{C}=\mathrm{N}$ (1638), $\nu \mathrm{S}=\mathrm{O}(1102,1025), \nu \mathrm{Ru}-\mathrm{S}$ (428); (c). ${ }^{1} \mathrm{H}$ NMR (400 MHz, $\mathrm{CDCl}_{3}$ ): $\delta=7.14$ (s, $2 \mathrm{H}, \mathrm{CH}_{4,5} \mathrm{Im}$ ), 5.05 (m, 2H, NCH), 3.56 (s, 12H, $\mathrm{CH}_{3}$ S-DMSO), 2.13-2.04 (m, 6H, $\mathrm{CH}_{2}{ }^{\mathrm{Octyl}}$ ), 2.03-1.95 (m, 6H, $\mathrm{CH}_{2}{ }^{\text {Octyl }}$ ), $1.74-1.65\left(\mathrm{~m}, 8 \mathrm{H}, \mathrm{CH}_{2}{ }^{\text {Octyl }}\right.$ ), $1.64-1.55$ (m, 8H, $\mathrm{CH}_{2}{ }^{\text {Octyl }}$ ) ppm. ${ }^{13} \mathrm{C} \mathrm{NMR}\left(100 \mathrm{MHz}, \mathrm{CDCl}_{3}\right): \delta=136.7\left(\mathrm{Im}-\mathrm{C}_{2}\right), 118.6\left(\mathrm{Im}-\mathrm{C}_{4,5}\right)$, 60.8 ( CHN), $46.1\left(\mathrm{CH}_{3}\right.$-S-dmso), $33.7\left(\mathrm{CH}_{2}{ }^{\text {octyl }}\right), 26.4\left(\mathrm{CH}_{2}{ }^{\text {octyl }}\right), 25.4$ $\left(\mathrm{CH}_{2}{ }^{\text {octyl }}\right), 23.8\left(\mathrm{CH}_{2}{ }^{\text {octyl }}\right)$ ppm. EPR: no signal was observed.

\subsection{Computational details}

The structure of the compounds under study were optimized and had their vibrational frequencies calculated using the density functional theory (DFT) at the level of the functional M06 [31], implemented in Gaussian 09 [32], using the basis set DGDZVP [33]. The structures were solvated using the IEFPCM model [34].

\subsection{ROMP procedure}

In a typical ROMP experiment, $1.1 \mu \mathrm{mol}$ of complex was dissolved in $\mathrm{CH}_{2} \mathrm{Cl}_{2}(2 \mathrm{~mL})$ with an appropriate amount of monomer (NBE, $5.5 \mathrm{mmol}$ ), followed by addition of carbene source (EDA, $31 \mu \mathrm{mol}$ ). The reaction mixture was stirred up to $60 \mathrm{~min}$ at $50{ }^{\circ} \mathrm{C}$ in a silicon oil bath. At room temperature, $5 \mathrm{~mL}$ of methanol was added and the polymer was filtered, washed with methanol and dried in a vacuum oven at $40{ }^{\circ} \mathrm{C}$ up to constant weight. The reported yields are average values from catalytic runs performed at least three times with $10 \%$ error at the most. The isolated polyNBEs were dissolved in THF for GPC data.

\subsection{ATRP procedure}

In a typical ATRP experiment, $12.3 \mu \mathrm{mol}$ of complex was placed in a 
Schlenk tube containing a magnet bar and capped by a rubber septum. Air was expelled by three vacuum-nitrogen cycles before appropriate amounts of monomer (MMA, $12.3 \mathrm{mmol}$ ), initiator (EBiB, $24.6 \mu \mathrm{mol}$ ), and toluene $(1 \mathrm{~mL})$ were added. All liquids were handled with dried syringes under nitrogen. The tube was capped under $\mathrm{N}_{2}$ atmosphere using Schlenk techniques, then the reaction mixture was immediately immersed in an oil bath previously heated to the desired temperature. The polymerizations were conducted at $85^{\circ} \mathrm{C}$. The samples were removed from the tube after certain time intervals using degassed syringes. The polymerization was stopped when the reaction mixture became very viscous. The reported conversions are average values from catalytic runs performed at least twice.

\section{Results and discussion}

\subsection{Synthesis and characterization}

The one-pot procedure described for 1,3-dicyclohexylimidazolium tetrafluoroborate could be seamlessly translated to the preparation of 1,3-dicycloalkylimidazolium tetrafluoroborate (1a, 1c, and 1d) from glyoxal, cycloalkylamine (cyclopentylamine, cycloheptylamine, and cyclooctylamine), paraformaldehyde, and tetrafluoroboric acid $[29,30]$. This synthesis protocol of NHC ligands 1a-1d is an optimized route from the procedure reported by Nolan and co-workers, while searching for bulky NHC ligands to coordinate in transition metal catalysts [35-40]. The corresponding products were obtained under mild conditions; their confirmation was demonstrated by spectroscopic data (Scheme 1). The ligands 1a-1d are stable, non-hygroscopic solid that could be easily purified by recrystallization from isopropanol with typical yields of $70 \%$.

Prior to the complexation step, these NHC precursors were suspended in dry THF and deprotonated with sodium hydride in the presence of a catalytic amount of potassium tert-butoxide at room temperature. Within $2 \mathrm{~h}$, the initially white solution became progressively pale yellow. Once the deprotonation step was completed, the suspensions were allowed to settle down and the inorganic byproduct was filtered off, along with any unreacted starting materials. The deprotonated imidazolium salts 1a-1d were reacted with an equimolar amount of $\left[\mathrm{RuCl}_{2}(\mathrm{~S}-\mathrm{dmso})_{3}(\mathrm{O}-\mathrm{dmso})\right]$ complex to obtain the NHC ruthenium(II) complexes 2a-2d in high yields (Scheme 2). The complexes 2a-2d were formed only in the powder form and non-hygroscopic, which was not suitable for single X-ray diffraction analysis. Further attempts to get crystals were not successful.

ESR spectra of the isolated compounds were silent and elemental analyses suggest five-coordinated complexes with the general formula the $\left[\mathrm{RuCl}_{2}(\mathrm{dmso})_{2}(\mathrm{NHC})\right]$; where $\mathrm{NHC}=1$,3-dicycloalkylimidazolium 1a-1d. Each ruthenium centre presents low spin $d^{6}$ electronic configuration with +2 oxidation state.

The infrared spectra were similar, with two strong bands in the region of $1102-1018 \mathrm{~cm}^{-1}$ assigned to the $\nu(\mathrm{S}=\mathrm{O})$ stretching vibrations. S-bonded dmso was evident from Ru-S stretching in $428 \mathrm{~cm}^{-1}$. These bands now support linkage of dmso to the ruthenium metal centre through sulphur, following the literature [28,41,42]. Bands in $1548-1552 \mathrm{~cm}^{-1}$ were attributed to $\nu(\mathrm{C}=\mathrm{C})$ of the imidazole ring. The bands in the region of 345 and $310 \mathrm{~cm}^{-1}$ were attributed to $\nu(\mathrm{Ru}-\mathrm{Cl})$ asymmetric and symmetric stretching vibrations, respectively, suggesting two cis-positioned $\mathrm{Cl}^{-}$ligands.

In the ${ }^{1} \mathrm{H}$ NMR spectra in $\mathrm{CDCl}_{3}$ for the synthesized ligands (1a-1d) and their complexes (2a-2d) are given in the experimental section. The peaks in the range 1.0-2.5 ppm for ligands $\mathbf{1 a - 1 d}$ and complexes $\mathbf{2 a - 2 d}$, as multiplets, are assignable to the $\mathrm{CH}_{2}$ groups hydrogens from the $\mathrm{N}$ cycloalkyl substituent. The singlet at $3.5 \mathrm{ppm}$ is assigned to the methyl groups of the S-bonded dmso. This signal indicated two equivalent Sdmso molecules trans-positioned to two $\mathrm{Cl}^{-}$ligands in the complexes 2a-2d. Additionally, the peaks at range 4.0-5.0 ppm for ligands 1a-1d and around 5.3 ppm for complexes $\mathbf{2 a - 2 d}$, as quintuplets, are assignable to the hydrogen attached to the carbon which connects the cycloalkyl substituent to the imidazole nitrogen. In the ${ }^{1} \mathrm{H}$ NMR spectra of ligands 1a-1d and complexes 2a-2d, the chemical shifts observed around 7.2-7.5 ppm for free ligands and at 7.0-7.2 ppm for complexes $\mathbf{2 a - 2 d}$ as singlets are assigned to the hydrogens present in the carbon double bond of the imidazole ring. Finally, the signal at 8.8-9.0 ppm refers to the hydrogen of the $\mathrm{C}_{2}$ carbon of the imidazole ring in the free ligands 1a-1d. These signals did not appear in the complexes 2a-2d as expected, confirming NHC carbene coordination to the ruthenium centre. In the ${ }^{13} \mathrm{C}$ NMR spectra, the carbon peaks between $23.7-134.3 \mathrm{ppm}$ for ligands 1a-1d and 24.0-138.3 ppm for complexes 2a-2d were observed.

Correlating the NMR data with the FTIR spectrum, which suggested that the two chloride ligands are cis-positioned, a square pyramidal geometry is assigned to Ru(II) centre in all complexes synthesized.

Electronic spectra of ligands 1a-1d (Fig. S1) and their complexes (Fig. 2) have been recorded in the $200-700 \mathrm{~nm}$ range in $\mathrm{CH}_{2} \mathrm{Cl}_{2}$. The formation of the complexes $\mathbf{2 a - 2 d}$ was also confirmed by electronic spectra. In the electronic spectra of the complexes $\mathbf{2 a - 2 d}$ show a band around $242 \mathrm{~nm}$ corresponding to intra-ligand $\pi \rightarrow \pi$ transition and another band of lower energy in the region $324 \mathrm{~nm}$ assignable to MLCT transition. The bands assigned to intra-ligand $\pi \rightarrow \pi$ transition show hypsochromic shifts relative to their free ligands. This displacement of the absorption bands of the complexes 2a-2d most likely originate from the metalation which increases the conjugation and delocalization of the whole electronic system and results in the energy change of the $\pi \rightarrow$ $\pi$ transition of the conjugated chromophore. These results clearly indicate that the ligand coordinates to metal centre, which are in accordance with the results of the other spectroscopic data.

The electrochemical activity of the complexes $\mathbf{2 a - 2} \mathbf{d}$ was studied by cyclic voltammetry in scan rate of $100 \mathrm{mV} \mathrm{s}^{-1}$ in $\mathrm{CH}_{2} \mathrm{Cl}_{2}$ solution containing $0.1 \mathrm{M} \mathrm{n}-\mathrm{Bu}_{4} \mathrm{NPF}_{6}$ supporting electrolyte in the potential range $300-1100 \mathrm{mV}$. Under these conditions the redox potential $\left(E_{1 / 2}\right)$

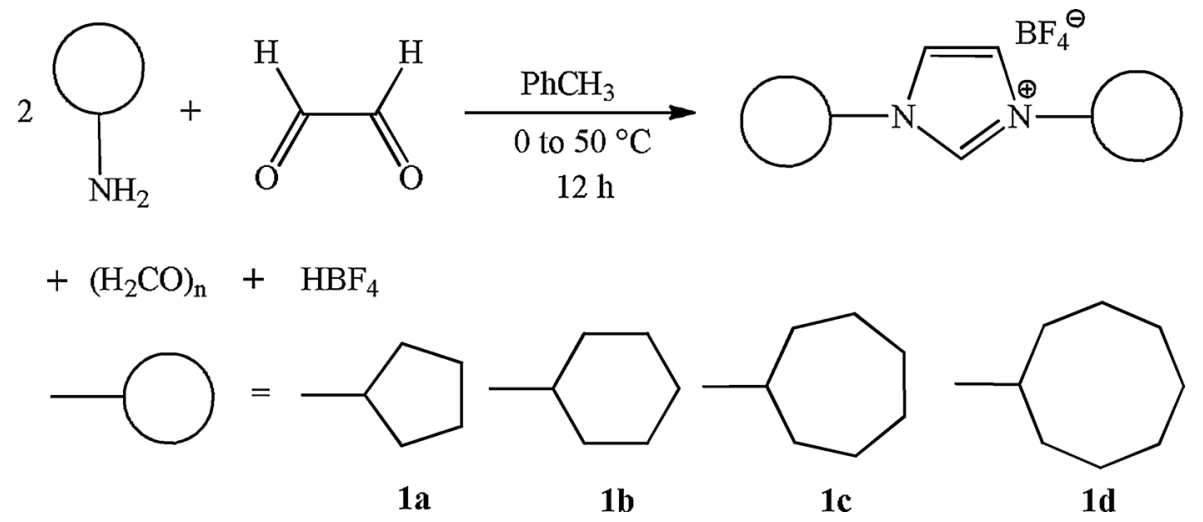

Scheme 1. Synthesis protocol of NHC ligands 1a-1d. 


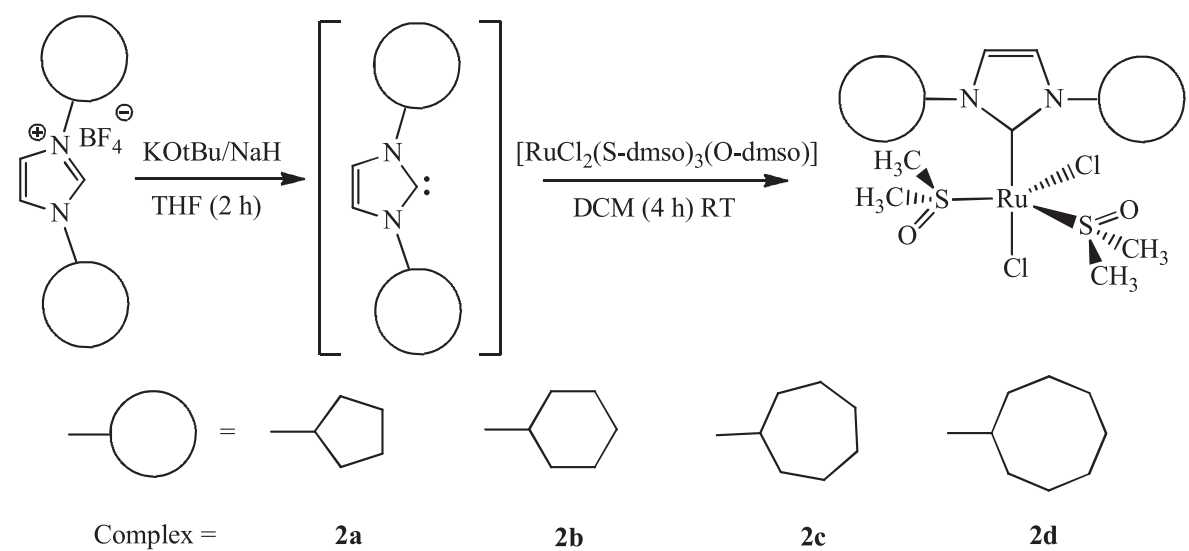

Scheme 2. Synthesis protocol of dimethyl sulfoxide ruthenium complexes bearing NHC ligands.

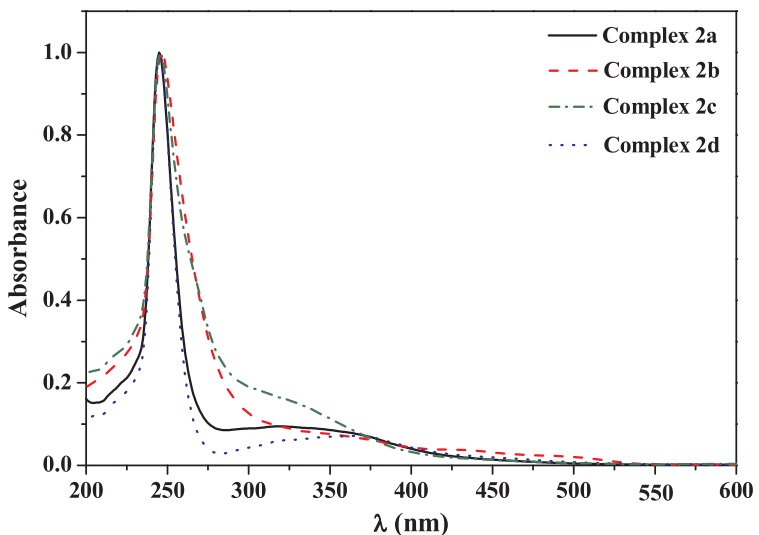

Fig. 2. Electronic spectra of the complexes 2a-2d in degassed $\mathrm{CH}_{2} \mathrm{Cl}_{2}$ solution at room temperature $\left([\mathrm{Ru}]=0.1 \mathrm{mmol} \mathrm{L}^{-1}\right)$.

Table 1

Cyclic voltammetry ${ }^{[\mathrm{a}]}$ results for complexes $\mathbf{2 a - 2 d .}$

\begin{tabular}{|c|c|c|c|c|}
\hline \multirow[t]{2}{*}{ Complex } & \multicolumn{3}{|l|}{$\mathrm{CV}$} & \multirow[b]{2}{*}{$\Delta E_{\mathrm{p}}(\mathrm{mV})$} \\
\hline & $E_{\mathrm{pa}}(\mathrm{mV})$ & $E_{\mathrm{pc}}(\mathrm{mV})$ & $E_{1 / 2}(\mathrm{mV})$ & \\
\hline $2 a$ & 726 & 641 & 683 & 85 \\
\hline $2 b$ & 720 & 658 & 694 & 62 \\
\hline $2 c$ & 695 & 616 & 655 & 79 \\
\hline $2 d$ & 723 & 649 & 686 & 74 \\
\hline
\end{tabular}

for the $\mathrm{Fc} / \mathrm{Fc}^{+}$couple occurred at $465 \mathrm{mV}$, with $\Delta E_{\mathrm{p}}=208 \mathrm{mV}$ (Fig. S2); the electrochemical data of the complexes $\mathbf{2 a - 2 d}$ are given in Table 1 and the representative cyclic voltammograms for the behaviours of the complexes are shown in Fig. 3. All the four NHC ruthenium complexes exhibit identical one-electron response corresponding to the $\mathrm{Ru}^{\mathrm{II} / \mathrm{III}}$ redox process in the $420-460 \mathrm{mV}$ range versus $\mathrm{Ag} / \mathrm{AgCl}$. Their peak-to-peak separations $\left(\Delta E_{\mathrm{p}}\right)$ are lower to the ferrocene-ferrocenium couple, indicating that these $\mathrm{Ru}^{\mathrm{II}} / \mathrm{Ru}^{\mathrm{III}}$ couples are facile and reversible. The $\Delta E_{\mathrm{p}}$ values are somewhat larger than the canonical value for ideal Nernstian behavior $(59 \mathrm{mV})$, indicating some reorganization of the coordination sphere of the ruthenium centre. This may reflect preferred coordination geometries for each redox state, $\mathrm{Ru}^{\mathrm{II}}$, $\mathrm{d}^{6}$ and $\mathrm{Ru}^{\mathrm{III}}, \mathrm{d}^{5}$. Lower oxidation potential values for complexes $\mathbf{2 a - 2 d}$ were obtained as compared with precursor $\left[\mathrm{RuCl}_{2}(\mathrm{~S}-\mathrm{dmso})_{3}(\mathrm{O}-\mathrm{dmso})\right]$ ( $E_{o x}=1520 \mathrm{mV}$ versus $\mathrm{Ag} / \mathrm{AgCl}$ ) and were associated with the occurrence of strong NHC $\sigma$-donation that destabilizes the HOMO orbital in the ground state in each case.

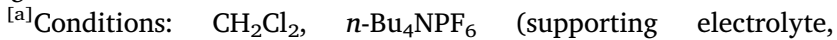
$\left.0.1 \mathrm{~mol} \mathrm{~L}^{-1}\right),[\mathrm{Ru}]=5 \mathrm{mmol} \mathrm{L}^{-1}$, scan rate $=100 \mathrm{mV} \mathrm{s}^{-1}$ ), platinum

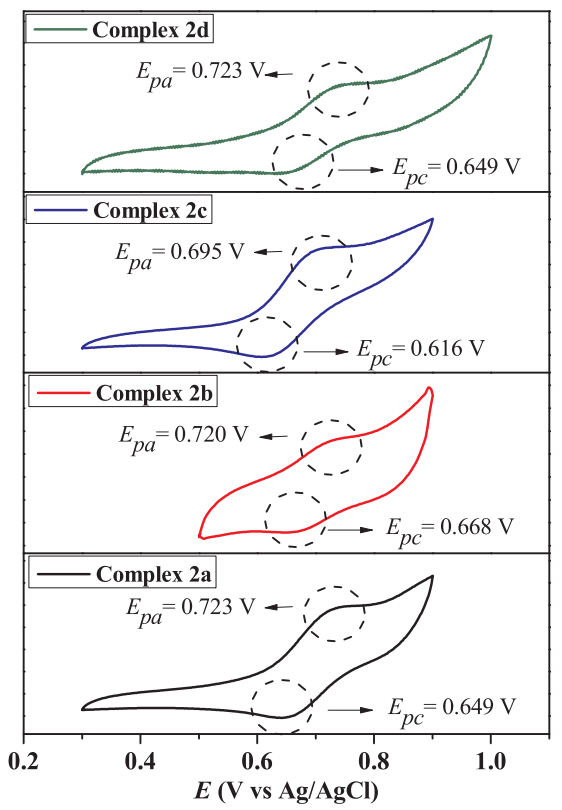

Fig. 3. Cyclic voltammograms of $\mathbf{2 a - 2 d}$ in $\mathrm{CH}_{2} \mathrm{Cl}_{2}$ at $25^{\circ} \mathrm{C}$. [Ru] $=10 \mathrm{mM} ; \quad[n$ $\left.\mathrm{Bu}_{4} \mathrm{NPF}_{6}\right]=0.1 \mathrm{M}$. Scanning anodically from $0.3 \mathrm{up}$ to $1.0 \mathrm{~V}$ at scan rate of $100 \mathrm{mV} \mathrm{s}^{-1}$.

disk and wire (working and auxiliary electrode), $\mathrm{Ag} / \mathrm{AgCl}$ (reference electrode). $E_{1 / 2}$ is the half-potential for the complex; $\Delta E_{\mathrm{p}}$ is the cathodic-anodic peak separation.

\subsection{ROMP reactions}

In order to assess the catalytic efficiency of dimethyl sulfoxide ruthenium(II) complexes 2a-2d, ROMP of norbornene (NBE) was attempted in $\mathrm{CH}_{2} \mathrm{Cl}_{2}$ at $50{ }^{\circ} \mathrm{C}$ with a $[\mathrm{NBE}] /[\mathrm{Ru}]$ ratio of 5000 (Scheme 3). Under these conditions, complexes 2a-2d were completely inefficient. In contrast, when ethyl diazoacetate (EDA) was added to generate metathetically active ruthenium-carbene species from $\left[\mathrm{RuCl}_{2}(\mathrm{~S}-\mathrm{dmso})_{2}(\mathrm{NHC})\right]$ precursors $2 \mathrm{a}-2 \mathrm{~d}$, ROMP occurred with moderate yields.

Fig. 4 shows the variation in the yield values of the isolated polymers as a function of time, in which an increase of the yield with increase of the polymerization time is observed for all the evaluated complexes. Initially, the catalytic activity of the complexes studied (2a2d) in ROMP of NBE was expected to increase as the number of $\mathrm{CH}_{2}$ groups increased in the cycloalkyl substituents, believing that $\mathrm{NHC} \rightarrow$ $\mathrm{Ru} \rightarrow$ olefin synergism would be favored for more efficient activation of the olefin (NBE). However, the catalytic activity of these complexes for ROMP of NBE showed an inverse behavior, in which it increased from 


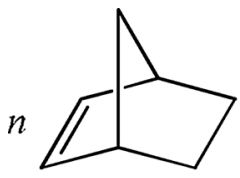

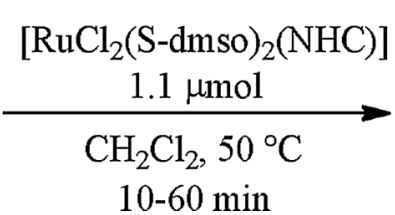

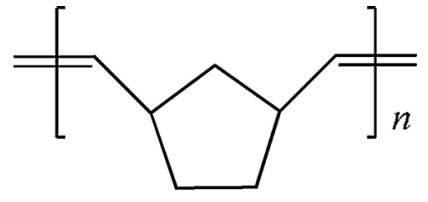

Scheme 3. ROMP of NBE catalysed by Ru-dmso complexes.

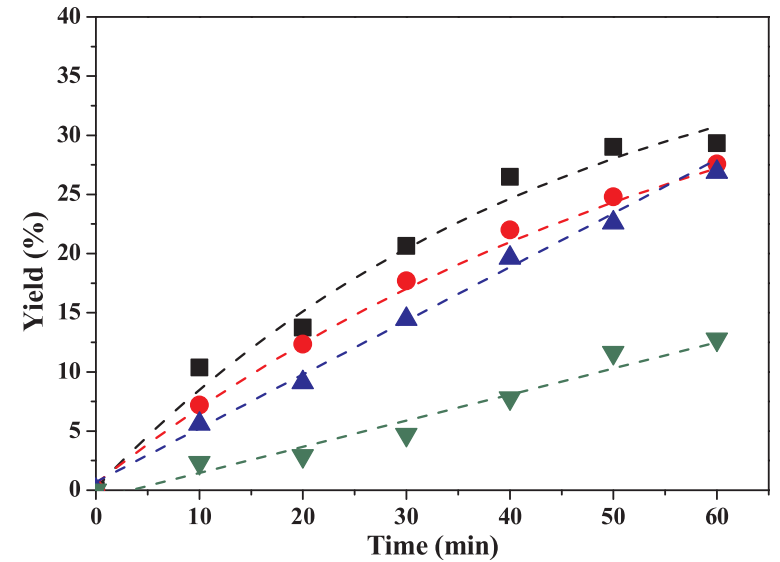

Fig. 4. Dependence of yield as a function of time for ROMP of NBE with $\mathbf{2 a}(\mathbf{\square}), \mathbf{2 b}(\mathbf{\bullet})$, 2c $(\Delta)$ and 2d $(\nabla) ;[\mathrm{NBE}] /[\mathrm{Ru}]=5000$ and $[\mathrm{EDA}] /[\mathrm{Ru}]=28$ in $\mathrm{CH}_{2} \mathrm{Cl}_{2}$ at $50{ }^{\circ} \mathrm{C}$.

the complex 2d (cyclooctyl) to complex 2a (cyclopentyl). We believe that this order of reactivity of the complexes may be associated with a kinetic dependence in the initiation step. Since pre-catalysts $\mathbf{2 a - 2 d}$ are

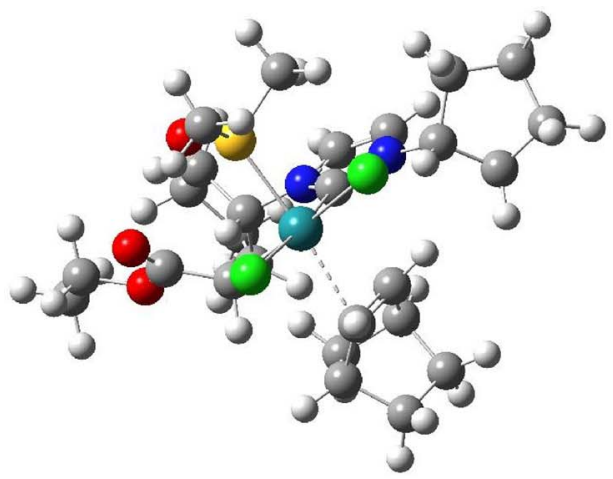

$2 \mathbf{a}$

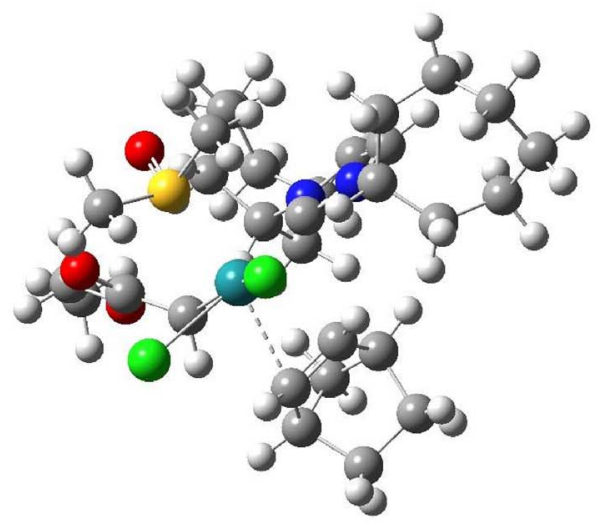

2c five-coordinated complexes, the success of ROMP requires the labilization of a cis-positioned ligand to the metal-carbene. In order to better understand the mechanism of the initiation step, the ROMP of NBE with complexes 2a-2d was performed in the presence of excess dmso ligand $(5 \mu \mathrm{L}$ of EDA with $[\mathrm{NBE}] /[\mathrm{dmso}] /[\mathrm{Ru}]=5000 / 20 / 1$ for $60 \mathrm{~min}$ at $50{ }^{\circ} \mathrm{C}$ ), in which no polyNBE yield was observed. This inertia indicates that the initiation step involves S-dmso loss from the ruthenium centre.

A computational investigation was carried out to explain the difference of activity between complexes $\mathbf{2 a - 2 d}$ in ROMP reactions. Fig. 5 shows the equilibrium position of the monomer from the ruthenium centre; as the number of $\mathrm{CH}_{2}$ groups in the cycloalkyl substituents increases, the equilibrium distance Ru-NBE increases: $2.421,2.448$, 2.448 , and $2.452 \AA$ for $\mathbf{2 a}, \mathbf{2 b}, \mathbf{2 c}$ and $\mathbf{2 d}$, respectively. The displacement of the dmso molecule from the ruthenium can be favored by the increase in the cycloalkyl group, however, nucleophilic attack of the $\mathrm{NBE}$ at the Ru centre is disfavored by increasing the cycloalkyl group due to steric reasons, which explains the decrease of the yield values in the following order: $\mathbf{2} \mathbf{d}<\mathbf{2} \mathbf{c}<\mathbf{2} \mathbf{b}<\mathbf{2} \mathbf{a}$. Further, an analysis of the molecular orbitals shows that there is no significant electronic density on the cycloalkanes and that their main role is in directing the approximation of the NBE to the ruthenium centre.

The NHC $\rightarrow \mathrm{Ru} \rightarrow \mathrm{S}$-dmso synergism makes the initiation step very

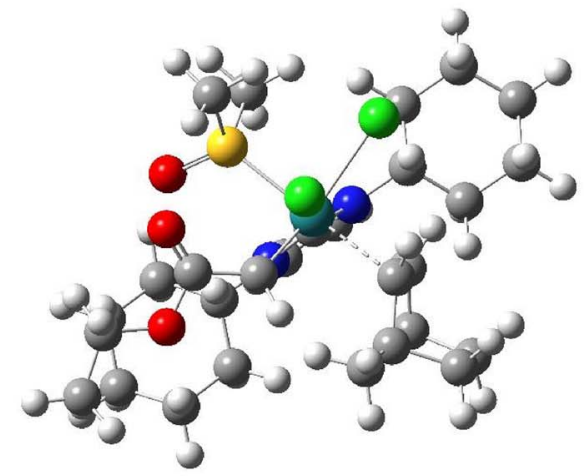

$2 \mathbf{b}$

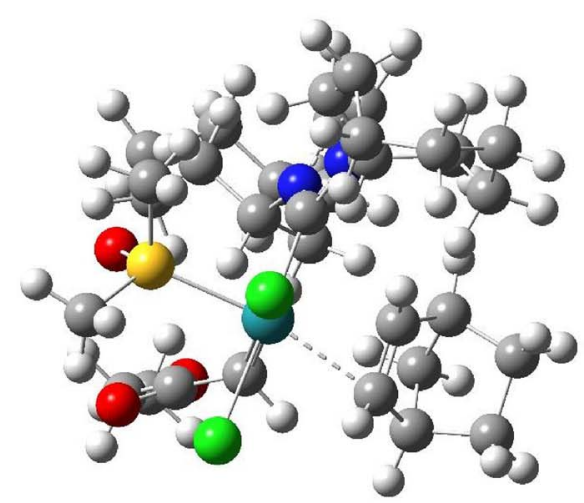

2d

Fig. 5. Representation of EDA and NBE coordinated to the precursor complexes 2a-2d. 
Table 2

Yield values and SEC data from the ROMP of NBE with 2a-2d at $50{ }^{\circ} \mathrm{C}$; [NBE]/ $[\mathrm{Ru}]=5000$ and $[\mathrm{EDA}] /[\mathrm{Ru}]=28$ with $1.1 \mu \mathrm{mol}$ of complex in $\mathrm{CH}_{2} \mathrm{Cl}_{2}$.

\begin{tabular}{lllll}
\hline Complex & Time (min) & Yield (\%) & $\mathrm{M}_{\mathrm{n}}\left(10^{3} \mathrm{~g} \mathrm{~mol}^{-1}\right)$ & PDI \\
\hline \multirow{2}{*}{$\mathbf{a}$} & 10 & 10.3 & 2.4 & 1.63 \\
& 20 & 13.7 & 4.5 & 2.78 \\
& 30 & 20.6 & 4.2 & 3.11 \\
& 40 & 26.5 & 4.1 & 3.16 \\
& 50 & 29.0 & 4.0 & 3.17 \\
$\mathbf{2 b}$ & 60 & 29.3 & 5.4 & 3.98 \\
& 10 & 7.2 & 4.0 & 2.57 \\
& 20 & 12.3 & 5.7 & 2.74 \\
& 30 & 17.7 & 4.3 & 3.50 \\
& 40 & 22.0 & 5.1 & 3.43 \\
& 50 & 24.8 & 4.5 & 3.54 \\
$\mathbf{2 c}$ & 60 & 27.6 & 5.2 & 3.19 \\
& 10 & 5.6 & 2.2 & 1.66 \\
& 20 & 9.1 & 2.4 & 2.14 \\
& 30 & 14.5 & 2.8 & 2.24 \\
& 40 & 19.6 & 3.1 & 2.55 \\
& 50 & 22.6 & 3.9 & 3.17 \\
$\mathbf{2 d}$ & 60 & 26.9 & 3.3 & 3.27 \\
& 10 & 2.3 & 3.8 & 1.82 \\
& 20 & 2.9 & 5.5 & 2.73 \\
& 30 & 4.7 & 4.6 & 2.28 \\
& 40 & 7.8 & 5.1 & 2.86 \\
& 50 & 11.6 & 4.3 & 2.62 \\
& 60 & 12.8 & 5.1 & 3.01 \\
\hline & & & &
\end{tabular}

slow, producing polyNBE with large dispersity. The PDI values of about 3.0 may be associated with a possible inefficiency of the initiation step; in other words, the great synergism becomes detrimental because the coordination of the olefin (NBE) to the ruthenium centre depends on the dmso ligand loss which should be fast and uniform. Consequently, chain growth occurs before all Ru units have initiated the ROMP reactions. In this way, a large dispersion in the size of the polymer chains was obtained. Although the PDI values were large, the isolated polyNBEs showed monomodal molecular weight distributions with molar weights in the range of $2.2 \times 10^{3}$ to $5.7 \times 10^{3} \mathrm{~g} \mathrm{~mol}^{-1}$ (Table 2).

Based on this, it is possible to infer that the difference in the reactivity of the complexes studied is directly related to the steric characteristics of the NHC ligands, which are modulated by their substituents (cycloalkyl groups). Upon metal-carbene formation, a S-dmso ligand leaves the complex, followed by the coordination of NBE to the carbene-Ru species. This associative pathway was confirmed by theoretical calculations. The formation of the Ru-EDA complex without the output of a dmso molecule is slightly favored (about $22 \mathrm{~kJ} / \mathrm{mol}$ ) in comparison with a dissociative mechanism. Further, the polymerization in the presence of dmso confirmed that the ROMP reaction did not occur, although the carbene complex formation took place. The ROMP will only occur when the dmso molecule undergoes discoordination from the metal centre (Scheme 4).

\subsection{ATRP reactions}

Next, we focused our attention on the atom-transfer radical polymerization (ATRP) of methyl methacrylate (MMA) initiated by ethyl-2bromoisobutyrate (Scheme 5). The complexes 2a-2d have properties that make them promising compounds for use as ATRP catalysts. They provide reversible or quasi-reversible $\mathrm{Ru}^{\mathrm{II}} / \mathrm{Ru}^{\mathrm{III}}$ couples at easily accessible potentials, as shown by the electrochemical data. They are fivecoordinate complexes with square pyramidal geometry, which makes it possible for a halide ligand to enter the coordination sphere. The polymerization of MMA via ATRP with complexes 2a-2d were performed as a function of time using a $[\mathrm{MMA}] /[\mathrm{EBiB}] /[\mathrm{Ru}]$ ratio of 1000/ $2 / 1$ molar ratio at $85^{\circ} \mathrm{C}$.

The MMA conversion values increase lineally as a function of time in all cases (Fig. 6). The catalytic activity of the complexes $\mathbf{2 a - 2 d}$ has increased with the increase of the $\mathrm{CH}_{2}$ groups on the cycloalkyl substituent. The complex $2 \mathrm{a}$ achieved a maximum conversion of $47 \%$ of polyMMA, and almost doubled with 2d, reaching $80 \%$ in $12 \mathrm{~h}$.

Kinetics studies of the polymerization of MMA mediated by the complexes 2a-2d show a linear correlation of $\ln \left([\mathrm{MMA}]_{0} /[\mathrm{MMA}]\right)$ as a function of time $\left(r^{2}=0.992,0.985,0.990\right.$, and 0.994 for $2 a, 2 b, 2 c$, and 2d, respectively) (Fig. 7). This linearity clearly indicates that the concentration of radicals remains constant during the polymerization of MMA. The slope in the first-order kinetic plots allowed us to calculate the kinetic constants of reactions mediated by each one of the complexes $\left(1.52 \times 10^{-5} \mathrm{~s}^{-1}\right.$ for $2 \mathrm{a}, 2.29 \times 10^{-5} \mathrm{~s}^{-1}$ for $\mathbf{2 b}$, $2.73 \times 10^{-5} \mathrm{~s}^{-1}$ for $2 \mathrm{c}$, and $3.70 \times 10^{-5} \mathrm{~s}^{-1}$ for $2 \mathrm{~d}$ ).

In this case, unlike the ROMP reactions, the catalytic activity of the complexes studied follows this trend: $\mathbf{2 a}<\mathbf{2} \mathbf{b}<\mathbf{2 c}<\mathbf{2 d}$, it is believed that the strong $\sigma$-donation of $\mathrm{NHC} \rightarrow \mathrm{Ru}$ favors the activation step in ATRP (reaction between the catalyst and initiator or dormant species). This order of reactivity observed indicates that the ATRP mechanism mediated by the complexes $\mathbf{2 a - 2 d}$ does not appear to involve the lability of S-dmso ligand from the coordination sphere.

The linear semilogarithmic plot of $\ln [\mathrm{MMA}]_{0} /[\mathrm{MMA}] \mathrm{t}$ versus time and the linear increase of molecular weight with conversion, in conjunction with moderate PDIs (Table 3), illustrates a certain level of control imparted by the complexes 2a-2d (Figs. 7 and 8). However, in repeated kinetic experiments molecular weights were observed to be much higher than the theoretical values, thereby revealing a low initiation efficiency. This is associated to the number of growing radical chains being lower than expected, resulting in an effective increase in the monomer concentration.

\section{Conclusions}

Four $N$-heterocyclic carbene $1 \mathbf{a}-1 \mathbf{d}$ and their respective complexes $\mathrm{RuCl}_{2}(\mathrm{~S}-\mathrm{dmso})_{2}$ (IPent)] (2a), $\left[\mathrm{RuCl}_{2}(\mathrm{~S}-\mathrm{dmso})_{2}(\mathrm{IHex})\right]$ (2b), $\left[\mathrm{RuCl}_{2}(\mathrm{~S}-\right.$ dmso $\left.)_{2}(\mathrm{IHept})\right] \quad$ (2c), and $\left[\mathrm{RuCl}_{2}(\mathrm{~S}-\mathrm{dmsO})_{2}(\mathrm{IOct})\right]$ (2d) were

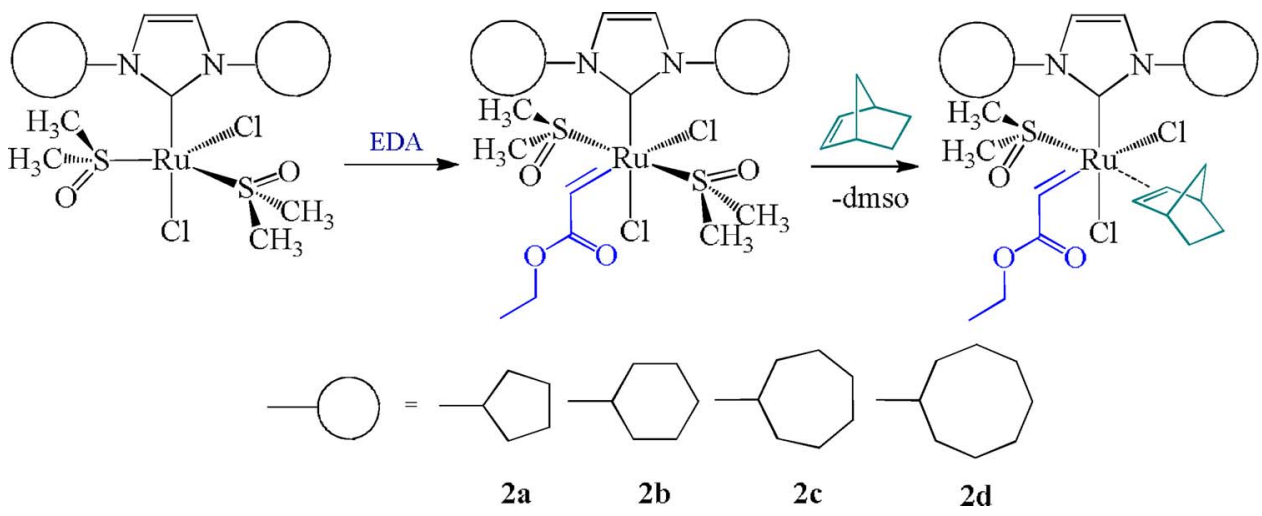

Scheme 4. Illustration of possible reaction steps for ROMP of NBE with the complexes $\mathbf{2 a - 2 d}$. 

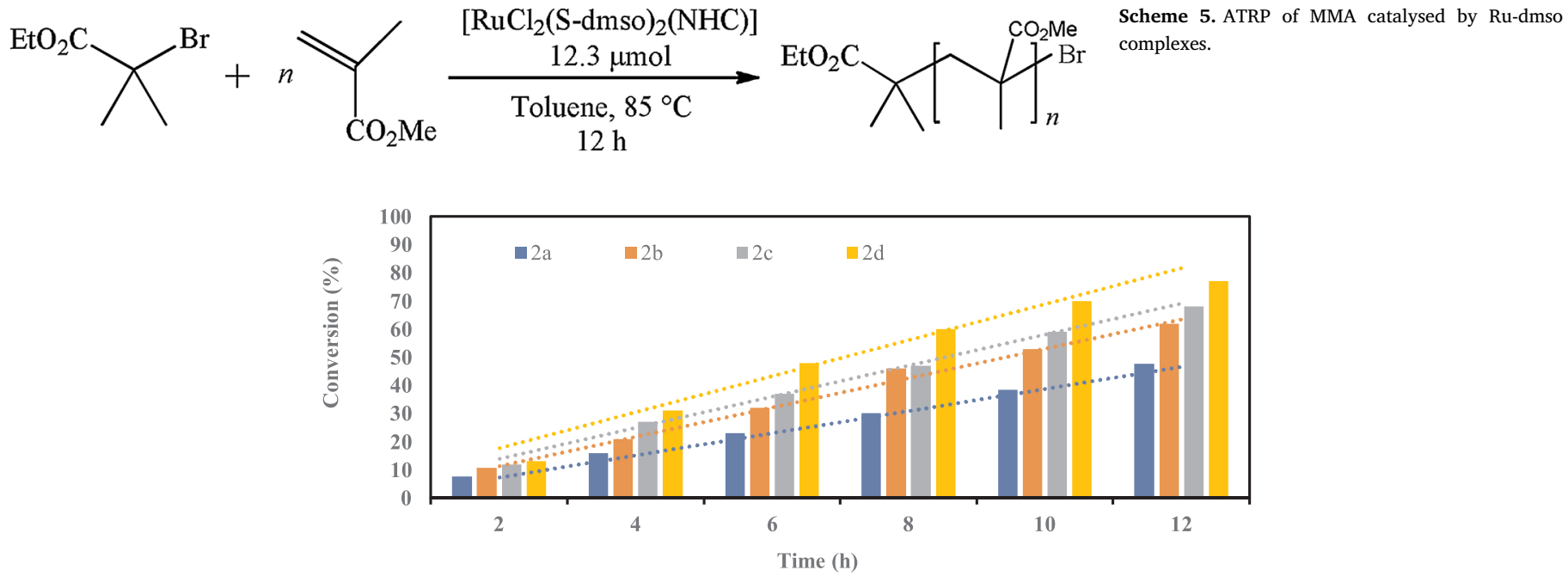

Fig. 6. Dependence of conversion on the reaction time for ATRP of MMA with $2 \mathrm{a}-2 \mathrm{~d}$; $[\mathrm{MMA}] /[\mathrm{EBiB}] /[\mathrm{Ru}]=1000 / 2 / 1$ with $12.3 \mu \mathrm{mol}$ of complex in toluene at $85^{\circ} \mathrm{C}$.

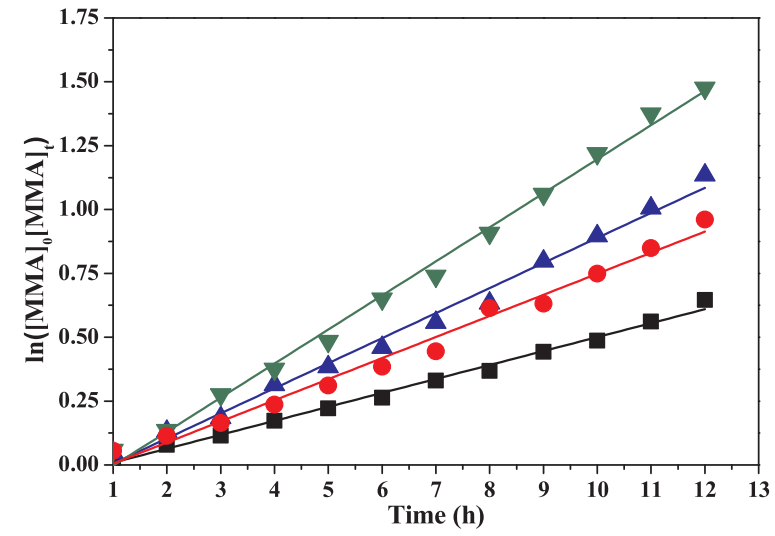

Fig. 7. Dependence of $\ln \left([\mathrm{MMA}]_{0} /[\mathrm{MMA}]\right)$ on the reaction time for ATRP of MMA with 2a ( $\mathbf{\square}), \mathbf{2 b}(\bullet), \mathbf{2 c}(\mathbf{\Delta})$ and $\mathbf{2 d}(\boldsymbol{\nabla})$; [MMA] $/[\mathrm{EBiB}] /[\mathrm{Ru}]=1000 / 2 / 1$ with $12.3 \mu \mathrm{mol}$ of complex in toluene at $85^{\circ} \mathrm{C}$.

Table 3

Conversion values and GPC data from the ATRP of MMA with 2a-2d; [MMA]/[EBiB]/ $[\mathrm{Ru}]=1000 / 2 / 1$ with $12.3 \mu \mathrm{mol}$ of complex in toluene at $85^{\circ} \mathrm{C}$.

\begin{tabular}{|c|c|c|c|c|}
\hline Complex & Time (h) & Conversion (\%) & $\mathrm{M}_{\mathrm{n}}\left(10^{4} \mathrm{~g} \mathrm{~mol}^{-1}\right)$ & PDI \\
\hline \multirow[t]{6}{*}{$2 \mathbf{a}$} & 2 & 7.6 & 8.5 & 1.92 \\
\hline & 4 & 15.9 & 12.3 & 1.79 \\
\hline & 6 & 23.1 & 17.4 & 1.68 \\
\hline & 8 & 30.8 & 22.0 & 1.66 \\
\hline & 10 & 38.5 & 26.4 & 1.62 \\
\hline & 12 & 47.6 & 36.0 & 1.45 \\
\hline \multirow[t]{6}{*}{$2 b$} & 2 & 10.8 & 27.3 & 1.43 \\
\hline & 4 & 21.0 & 37.2 & 1.38 \\
\hline & 6 & 31.9 & 42.4 & 1.36 \\
\hline & 8 & 45.8 & 48.7 & 1.31 \\
\hline & 10 & 52.7 & 52.3 & 1.20 \\
\hline & 12 & 61.7 & 63.1 & 1.17 \\
\hline \multirow[t]{6}{*}{$2 c$} & 2 & 12.3 & 16.2 & 1.31 \\
\hline & 4 & 26.9 & 25.6 & 1.21 \\
\hline & 6 & 36.8 & 32.1 & 1.15 \\
\hline & 8 & 46.9 & 38.9 & 1.10 \\
\hline & 10 & 59.1 & 48.2 & 1.10 \\
\hline & 12 & 67.8 & 56.9 & 1.10 \\
\hline \multirow[t]{6}{*}{$2 d$} & 2 & 12.7 & 6.9 & 1.32 \\
\hline & 4 & 31.3 & 16.4 & 1.22 \\
\hline & 6 & 47.8 & 22.0 & 1.17 \\
\hline & 8 & 59.6 & 26.4 & 1.13 \\
\hline & 10 & 70.5 & 36.0 & 1.10 \\
\hline & 12 & 77.1 & 41.1 & 1.09 \\
\hline
\end{tabular}

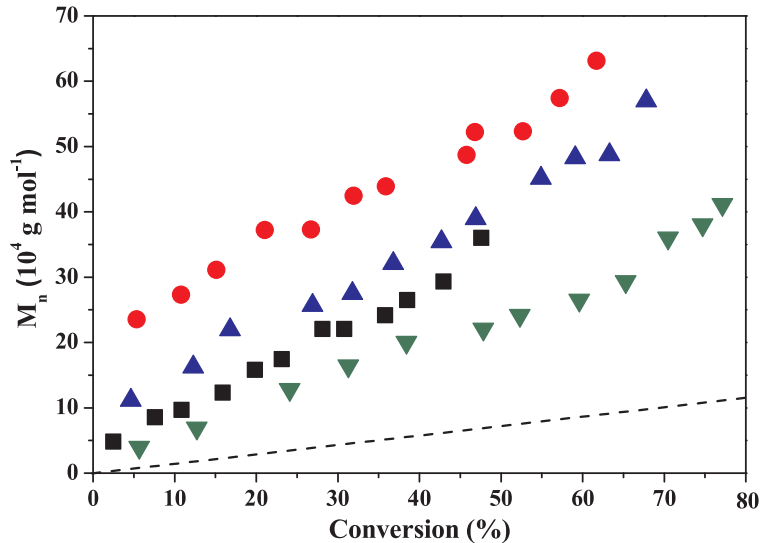

Fig. 8. Dependence of $M_{n}$ and PDI on the conversion for ATRP of MMA with 2a ( $\square$ ), $\mathbf{2 b}$ ( ), 2c $(\boldsymbol{\Lambda})$ and $2 \mathrm{~d}(\boldsymbol{\nabla})$; [MMA]/[EBiB] $/[\mathrm{Ru}]=1000 / 2 / 1$ with $12.3 \mu \mathrm{mol}$ of complex in toluene at $85{ }^{\circ} \mathrm{C} . \mathrm{M}_{\mathrm{n} \text { (theor) }}$ (black dashed-line).

successfully synthesized. Ligands 1a-1d were characterized by infrared, UV-vis and ${ }^{1} \mathrm{H}$ and ${ }^{13} \mathrm{C}$ NMR spectroscopy, whereas complexes 2a-2d were characterized by infrared, UV-vis and ${ }^{1} \mathrm{H}$ and ${ }^{13} \mathrm{C}$ NMR spectroscopy, elementary analysis, and cyclic voltammetry. It was concluded that two DMSO molecules have been replaced by a $N$-heterocyclic carbene in the coordination sphere, leading to five-coordinated complexes.

The complexes 2a-2d demonstrated moderate catalytic activities as catalytic precursors in ROMP of NBE at $50{ }^{\circ} \mathrm{C}$ with $[\mathrm{NBE}] /[\mathrm{Ru}]$ ratio of 5000 in the presence of $5 \mu \mathrm{L}$ of EDA for 5-60 min. The catalytic activity of complexes 2a-2d in ROMP increased as the $\mathrm{CH}_{2}$ group decreased in the cycloalkyl substituents, that means from $2 \mathbf{d}$ to $2 \mathbf{a}$. This order of reactivity is associated with a kinetic dependence at the initiation step, which the departure of the S-dmso ligand from the metal centre is involved in the rate limiting step of the reaction. The electronic synergism induced by the strong $\sigma$-donation of the NHC and the $\pi$-acceptor S-dmso (NHC $\rightarrow \mathrm{Ru} \rightarrow \mathrm{S}$-dmso) contributed to the stability of the complexes 2a2d. The nucleophilic attack of the NBE at the Ru centre is disfavored by increasing the cycloalkyl group due to steric reasons, which explains the decrease of the yield values in the following order: $2 d<2 c<$ $\mathbf{2 b}<2 \mathbf{a}$.

The polymerization of MMA mediated by the complexes $\mathbf{2 a - 2 d}$ was performed using a $[\mathrm{MMA}] /[\mathrm{EBiB}] /[\mathrm{Ru}]=1000 / 2 / 1$ molar ratio at $85^{\circ} \mathrm{C}$. Those complexes display activity as mediators for the controlled radical polymerization of MMA following an ATRP mechanism. The molecular weight of polyMMA increased with conversion, with 
decreasing PDI values with all complexes, which illustrates a certain level of control imparted by the complexes 2a-2d.

\section{Acknowledgement}

The authors are indebted to the financial support from FAPESP (Proc. 2013/10002-0).

\section{Appendix A. Supplementary data}

Supplementary data associated with this article can be found, in the online version, at http://dx.doi.org/10.1016/j.mcat.2018.01.032.

\section{References}

[1] R.H. Crabtree, The Organometallic Chemistry of the Transition Metals, Wiley, New York, 1988.

[2] L.A. Thompson, J. Ellman, Chem. Rev. 96 (1996) 555-560.

[3] D.L. Boger, W. Chai, Q. Jin, J. Am. Chem. Soc. 120 (1998) 7220-7225.

[4] K.V. Bernaerts, F.E. Du Prez, Prog. Polym. Sci. 31 (2006) 671-722.

[5] V. Dragutan, I. Dragutan, J. Organomet. Chem. 691 (2006) 5129-5147.

[6] Y. Yagci, M.A. Tasdelen, Prog. Polym. Sci. 31 (2006) 1133-1170.

[7] R.G. Lopez, F. D’Agosto, C. Boisson, Prog. Polym. Sci. 32 (2007) 419-454.

[8] J.B. Matson, R.H. Grubbs, Macromolecules 41 (2008) 5626-5631.

[9] G. Morandi, S. Piogé, S. Pascual, Mater. Sci. Eng. C 29 (2009) 367-371.

[10] D.E. Fogg, E.N. Dos Santos, Coord. Chem. Rev. 248 (2004) 2365-2379.

[11] C.W. Bielawski, R.H. Grubbs, Prog. Polym. Sci. 32 (2007) 1-29.

[12] K. Nomura, M.M. Abdellatif, Polymer 51 (2010) 1861-1881.

[13] D. Yang, W. Huang, J.H. Yu, J.S. Jiang, L.Y. Zhang, M.R. Xie, Polymer 51 (2010) 5100-5106.

[14] L.C. So, S. Faucher, S. Zhu, Prog. Polym. Sci. 39 (2014) 1196-1234.

[15] F. di Lenaa, K. Matyjaszewski, Prog. Polym. Sci. 35 (2010) 959-1021.

[16] M. Kamigaito, J. Polym. 43 (2011) 105-120.

[17] F. Simal, S. Delfosse, A. Demonceau, A.F. Noels, K. Denk, F.J. Kohl, T. Weskamp, W.A. Herrmann, J. Chem. Eur. 8 (2002) 3047-3052.

[18] J.M.E. Matos, B.S. Lima Neto, J. Mol. Catal. A 222 (2004) 81-85.

[19] J.M.E. Matos, B.S. Lima Neto, J. Mol. Catal. A 259 (2006) 286-291.

[20] J.L.S. Sá, B.S. Lima Neto, J. Mol. Catal. A 304 (2009) 187-190.

[21] J.L.S. Sá, L.H. Vieira, E.S.P. Nascimento, B.S. Lima Neto, Appl. Catal. A 374 (2010) $194-200$
[22] V.P. Carvalho Jr., C.P. Ferraz, B.S. Lima Neto, J. Mol. Catal. A 333 (2010) 46-53.

[23] H.K. Chaves, C.P. Ferraz, V.P. Carvalho Jr., B.S. Lima Neto, J. Mol. Catal. A 385 (2014) 46-53.

[24] L.R. Fonseca, E.S.P. Nascimento, J.L.S. Sá, B.S. Lima Neto, New J. Chem. 39 (2015) 4063-4069.

[25] R.A.N. Silva, P. Borim, L.R. Fonseca, B.S. Lima Neto, J.L.S. Sá, V.P. Carvalho Jr., Catal. Lett. 147 (2017) 1144-1152.

[26] P. Borim, B.S. Lima Neto, B.E. Goi, V.P. Carvalho Jr., Inorg. Chim. Acta 456 (2017) $171-178$

[27] M.B.A. Afonso, L.G. Gonçalves, P. Borim, B.E. Goi, V.P. Carvalho Jr., J. Braz. Chem. Soc. 28 (2017) 1407-1413.

[28] I.P. Evans, A. Spencer, G. Wilkinson, J. Chem. Soc. Dalton Trans. (1973) 204-209.

[29] R.H. Archer, J.R. Carpenter, S.-J. Hwang, A.W. Burton, C.-Y. Chen, S.I. Zones, M.E. Davis, Chem. Mater. 22 (2010) 2563-2572.

[30] M. Hans, J. Wouters, A. Demonceau, L. Delaude, J. Chem. Eur. 21 (2015) 10870-10877.

[31] Y. Zhao, D.G. Truhlar, Theor. Chem. Accounts 120 (2006) 215-241.

[32] M.J. Frisch, G.W. Trucks, H.B. Schlegel, G.E. Scuseria, M.A. Robb, J.R. Cheeseman, G. Scalmani, V. Barone, B. Mennucci, G.A. Petersson, H. Nakatsuji, M. Caricato, X. Li, H.P. Hratchian, A.F. Izmaylov, J. Bloino, G. Zheng, J.L. Sonnenberg, M. Hada, M. Ehara, K. Toyota, R. Fukuda, J. Hasegawa, M. Ishida, T. Nakajima, Y. Honda, O. Kitao, H. Nakai, T. Vreven, J.A. Montgomery, Jr., J.E. Peralta, F. Ogliaro, M. Bearpark, J.J. Heyd, E. Brothers, K.N. Kudin, V.N. Staroverov, T. Keith, R. Kobayashi, J. Normand, K. Raghavachari, A. Rendell, J.C. Burant, S.S. Iyengar, J. Tomasi, M. Cossi, N. Rega, J.M. Millam, M. Klene, J.E. Knox, J.B. Cross, V. Bakken, C. Adamo, J. Jaramillo, R. Gomperts, R.E. Stratmann, O. Yazyev, A.J. Austin, R. Cammi, C. Pomelli, J.W. Ochterski, R.L. Martin, K. Morokuma, V.G. Zakrzewski, G.A. Voth, P. Salvador, J.J. Dannenberg, S. Dapprich, A.D. Daniels, O. Farkas, J.B. Foresman, J.V. Ortiz, J. Cioslowski, D.J. Fox, Gaussian 09, Revision E.01, Gaussian, Inc., Wallingford CT, 2013.

[33] N. Godbout, D.R. Salahub, J. Andzelm, E. Wimmer, Can. J. Chem. 70 (1992) 560-571.

[34] J. Tomasi, B. Mennucci, E. Cancès, J. Mol. Struct. (Theochem.) 464 (1999) $211-226$

[35] J. Huang, S.P. Nolan, J. Am. Chem. Soc. 121 (1999) 9889-9890.

[36] P. de Frémont, N. Marion, S.P. Nolan, Coord. Chem. Rev. 253 (2009) 862-892.

[37] N. Marion, S.P. Nolan, Chem. Soc. Rev. 37 (2008) 1776-1782.

[38] S. Díez-González, N. Marion, S.P. Nolan, Chem. Rev. 109 (2009) 3612-3676.

[39] X. Bantreil, S.P. Nolan, Nat. Protoc. 6 (2011) 69-77.

[40] S.P. Nolan, N-Heterocyclic Carbenes Effective Tools for Organometallic Synthesis, Wiley-VCH, Weinheim, 2014.

[41] E. Alessio, Chem. Rev. 104 (2004) 4203-4242.

[42] M. Calligaris, O. Carugo, Chem. Rev. 153 (1996) 83-154. 